\title{
Virtual Reality Versus Conventional Treatment of Reaching Ability in Chronic Stroke: Clinical Feasibility Study
}

\author{
Mindy F. Levin • Osnat Snir • Dario G. Liebermann • \\ Harold Weingarden $\cdot$ Patrice L. Weiss
}

To view enhanced content go to www.neurologytherapy-open.com

Received: June 12, 2012 / Published online: August 24, 2012

(C) The Author(s) 2012. This article is published with open access at Springerlink.com

\section{ABSTRACT}

Introduction: The objective of this study was to evaluate the potential of exercises performed in a $2 \mathrm{D}$ video-capture virtual reality (VR) training environment to improve upper limb motor

NIH Clinical Trial Registration: NCT01388400.

M. F. Levin (ه)

School of Physical and Occupational Therapy, Faculty of Medicine, 3654 Promenade Sir William Osler, Montreal, QC H3G 1Y5, Canada e-mail: mindy.levin@mcgill.ca

\section{F. Levin}

Center for Interdisciplinary Research in

Rehabilitation, Montreal, Canada

O. Snir

Department of Occupational Therapy,

Sackler Faculty of Medicine,

Tel Aviv University, Tel Aviv, Israel

Present Address:

O. Snir

Hannah Khoushy Child Development Center, Bnai Zion Medical Center, Haifa, Israel ability in stroke patients compared to those performed in conventional therapy.

Methods: A small sample randomized control trial, in an outpatient rehabilitation center with 12 patients with chronic stroke, aged 33-80 years, who were randomly allocated to video-capture VR therapy and conventional therapy groups. All patients participated in

D. G. Liebermann

Department of Physical Therapy,

Sackler Faculty of Medicine,

Tel Aviv University,

Tel Aviv, Israel

H. Weingarden

Department of Neurological Rehabilitation,

Sheba Medical Center, Tel Hashomer,

Israel

\section{P. L. Weiss}

Department of Occupational Therapy,

Faculty of Social Welfare and Health Sciences,

University of Haifa,

Haifa, Israel 
four clinical evaluation sessions (pre-test 1, pre-test 2, post-test, follow-up) and nine 45-minute intervention sessions over a 3-week period. Main outcomes assessed were Body Structure and Function (impairment: FuglMeyer Assessment [FMA]; Composite Spasticity Index [CSI]; Reaching Performance Scale for Stroke), Activity (Box and Blocks; Wolf Motor Function Test [WMFT]), and Participation (Motor Activity Log) levels of the International Classification of Functioning.

Results: Improvements occurred in both groups, but more patients in the VR group improved upper limb clinical impairment (FMA, CSI) and activity scores (WMFT) and improvements occurred earlier. Patients in the VR group also reported satisfaction with the novel treatment.

Conclusions: The modest advantage of VR over conventional training supports further investigation of the effect of video-capture VR or VR combined with conventional therapy in larger-scale randomized, more intense controlled studies.

Keywords: Clinical outcomes; Intervention; Reaching; Stroke; Virtual reality

\section{INTRODUCTION}

Over one million people experience a new stroke every year in Europe and the United States and between $30 \%$ and $66 \%$ of those affected have persistent deficits in upper limb (UL) function 6 months after stroke [1], which affects the ability of individuals to participate in activities of daily living and diminishes their quality of life [2]. The aim of rehabilitation is to limit post-stroke functional impairments that result from brain damage and to enlarge cortical representation and functional connectivity through neuroplastic mechanisms.
Research has focused on exploring ways to drive and shape neuroplasticity to improve functional outcomes after stroke. For example, task-specific training causes reorganization in sensory and motor cortices in adult mammals [3] and enhanced learning occurs when participants practice a variety of related tasks $[4,5]$. Motor learning is largely dependent on the type of movements practiced [6], intensity of practice [7] as well as environmental context in which practice occurs [8], including feedback [9]. These key elements of motor learning need to be integrated into rehabilitation paradigms aimed at motor recovery to maximally engage neuroplastic mechanisms $[8,10]$.

Virtual reality (VR) is a computer technology incorporating relevant feedback into simulated environments [11]. For UL motor rehabilitation, users interact with virtual objects directly via hand/body movements or through haptic or nonhaptic interfaces (e.g., glove, joystick, mouse), and perform actions that engender a feeling of being present in the simulated environment. VR may facilitate the application of motor learning and neuroplasticity principles during rehabilitation by adjusting stimuli to respond to actions in real-time and by incorporating and manipulating feedback [12].

Although studied as an evaluation and treatment tool for stroke for 15 years, evidence regarding the effectiveness of VR applications for rehabilitation is still sparse. VR-based rehabilitation is a relatively young, interdisciplinary field whose trajectory can be modeled by the Technology Hype Cycle described by the Gartner Group and applied to this field first by Rizzo and Kim [12, 13]. The earliest VR studies reported primarily on the development of novel applications and the demonstration of their feasibility and usability on small numbers of participants. As the field developed, the focus 
of research was directed towards small studies, often without a control group. One study evaluated the effects of a 4-week VR-based intervention (60 min/day, 5 days/week) on 10 patients with chronic stroke [14]. The UL exercise intervention, provided by a videocapture VR system (IREX ${ }^{\circledR}$, GestureTek, Inc., Toronto, Canada) using a variety of games, resulted in cortical reorganization according to fMRI scans.

Different types of VR environments have system-specific attributes but their relative benefits are largely unidentified. These systems have been described in the literature [15-19] and systematic reviews [20-23], which have evaluated the strength of evidence concerning the effectiveness of VR as a tool for stroke rehabilitation. The majority of studies concerned individuals who were being treated to improve UL recovery. Each review concluded that while the data were promising, there is a need to improve the level of research evidence by carrying out randomized control trials (RCT).

Most systematic reviews have included a heterogeneous mix of VR applications under the common theme of "VR treatments" (e.g., [15]). Variations include 2D and 3D interactive, video-capture, keyboard- or mouse-based interfaces, and recreational game systems viewed on monitors, screens, or through headmounted displays (HMD). It is likely that training in diverse VR environments leads to different functional outcomes due to differences in viewing media and type of task practice (e.g., perception of object location [24, 25]). For example, reaching movements made in a video-capture $2 \mathrm{D}$ environment viewed on a large screen were shorter, less straight, less accurate, and involved smaller shoulder and elbow joint excursions compared to those performed in an equivalent physical environment [26]. In contrast, HMD-viewed reaching movements in $3 \mathrm{D}$ VR were more similar to those made in a physical environment [27]. Because this heterogeneity makes the relative advantages and drawbacks of different VR platforms difficult to assess, the authors focused on determining the effects of therapy in a single type of VR environment (2D video-capture) on UL motor improvements in patients with stroke, compared to an equivalent amount of practice in a conventional training environment.

Before proceeding with a large-scale RCT, it is important to identify clinical benefits associated with practicing movements that may differ in quality than those performed in a physical environment. The authors designed a small sample RCT to compare conventional versus $2 \mathrm{D}$ video-capture VR-based interventions for treating reaching deficits in patients with chronic stroke [28]. Assuming that the environmental context in which movement is practiced would encourage patients to engage in more meaningful practice and that the virtual environment (VE) provides enhanced feedback (e.g., [29]), the authors hypothesized that stroke patients practicing movements in VR would have greater clinical UL motor improvements than those practicing in a physical environment.

\section{METHODS}

\section{Participants}

Patients were included if they had sustained a unilateral left- or right-sided stroke more than 3 months previously, had no hemispatial neglect or uncorrected visual field deficits, including hemianopia, and could understand and follow instructions (no receptive aphasia, mini-mental state evaluation >25) [30]. Participants were excluded if they had 
shoulder or arm pain, or lack of endurance as judged by their treating physician. Of 50 eligible patients, 14 (33-80 years, 10 months to 5 years after first stroke) were recruited from discharge lists of a large rehabilitation center and randomly allocated to one of two intervention groups having the same therapeutic goals: VR $(n=8)$ and Conventional $(n=6)$ (Fig. 1). Randomization was carried out using a coin toss by an individual who was not involved in either participant assessment or intervention. Two patients withdrew from the VR group before commencement of the intervention because of transportation and financial difficulties (see Fig. 1-consort diagram). All participants signed informed consent forms approved by the Institutional Ethics Review Board.

\section{Procedures}

Four clinical evaluations and nine intervention sessions were delivered by different personnel. A clinician (occupational therapist), experienced in neurological rehabilitation and blinded as to treatment group allocation, performed the entire battery of tests on individual subjects. All clinical tests used have previously published evidence of acceptable levels of validity and inter-rater reliability. Two clinical evaluations separated by 1 week were performed before the intervention: one was done immediately after and one was done 1 month after the intervention.

During the intervention sessions, VR therapy focused on goal-directed reaching tasks by the affected arm via virtual games and a

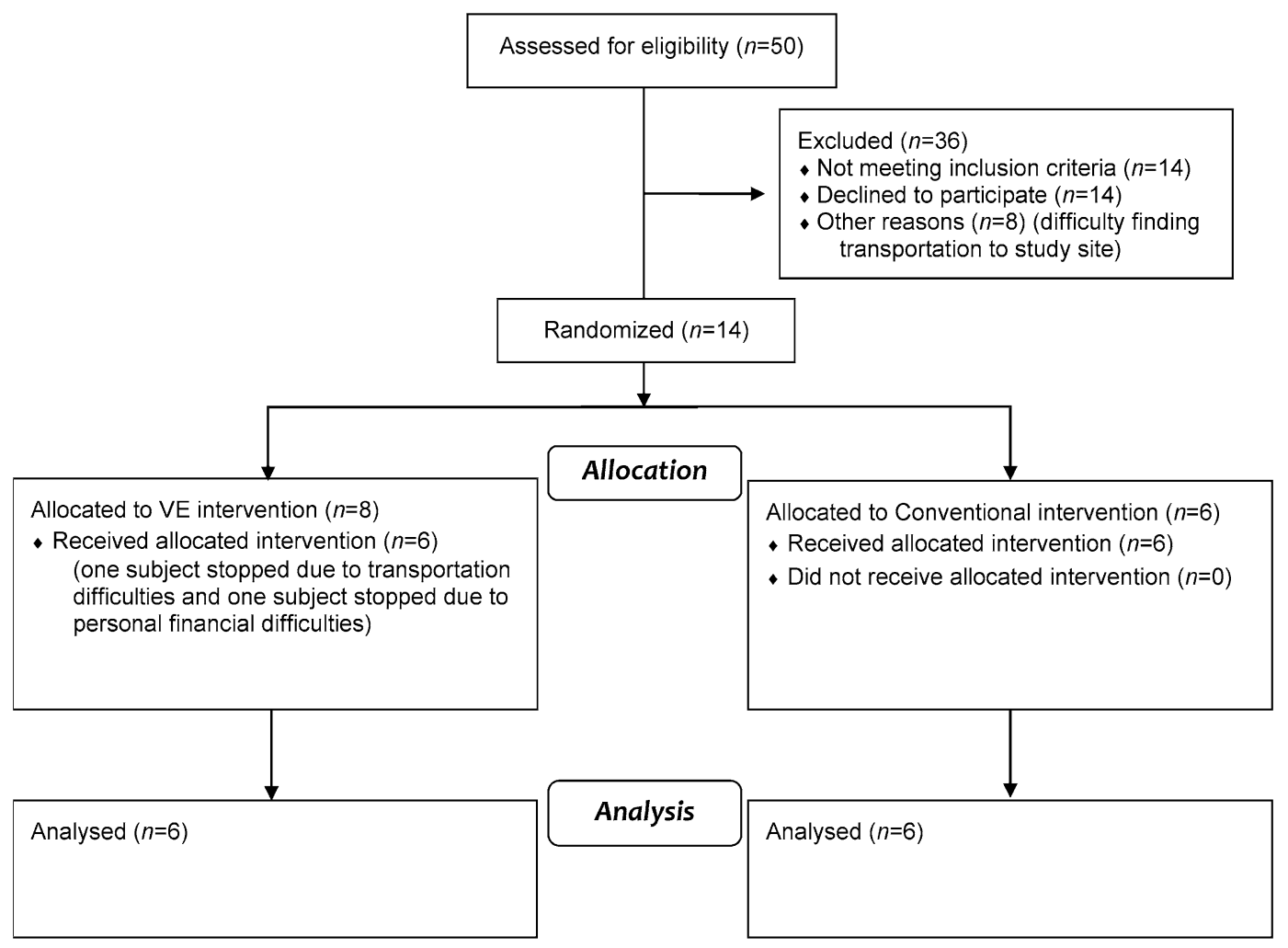

Fig. 1 Consort statement 
virtual supermarket (e.g., Birds \& Balls, Soccer, Volleyball, VMall) [31]. The reaching movements combined shoulder flexion to $\sim 130^{\circ}$, shoulder abduction to $\sim 60^{\circ}$, elbow extension to $\sim 180^{\circ}$, and wrist flexion and extension. Reaching movements were made into all areas of the arm workspace (e.g., ipsilateral, contralateral, midline, upper, and lower) to accomplish discrete and sequential reaching movements. Practice in the VE did not include grasping and manipulation tasks. Conventional therapy consisted of occupational therapy, including exercises involving reaching for and holding cones, cups, and other objects in all motion planes with and without external loading. These tasks were performed in a standard clinical treatment room.

The two types of therapy were equivalent in duration and type of feedback provided by the therapist concerning the quality of the reaching movements (e.g., amount of elbow extension, shoulder flexion) as well as the use of compensatory movements (e.g., trunk displacement). Participants in both environments were encouraged to work as hard as possible but the number of trials was not prescribed to avoid making the activities artificial. For both groups, the initial level of task difficulty was matched to patient impairment level and increased throughout the intervention to ensure that practice remained challenging to the individual.

\section{Instruments}

The VR therapy was done on the Gesture Xtreme $^{\circledR}$ (GestureTek, Inc. Toronto, Canada) video-capture system [19]. Users stood or sat in a demarcated area with a chroma-key backdrop and viewed a simulated VE on a $34^{\prime \prime}$ screen. The user's image was recorded and displayed within the VE, which responded to user gestures in real-time.

\section{Primary Outcome Measures}

Primary outcomes were clinical measures of UL performance at three levels of the International Classification of Function [32]. At the Body Structure and Function level, UL impairment was assessed with Fugl-Meyer Arm Scale (FMA) [33] (total score $=66$ ), spasticity in elbow flexors was assessed with the Composite Spasticity Index (CSI) [34] in which scores of 0-6, 7-9, and 10-16 correspond to mild, moderate, and severe spasticity respectively and motor compensations were assessed with the Reaching Performance Scale for Stroke (RPSS) [35], which evaluated six movement components for a total score of 18 . To assess the UL Activity level, the authors used the Box and Blocks test (BBT) [36] in which the number of blocks transferred by the more affected hand was expressed as a percentage of the number transferred by the less affected hand and the Wolf Motor Function Test (WMFT) [37], which assessed 15 arm function tasks. For the WMFT, results are reported as the mean Functional Abilities Scale Score and the mean time score. At the Performance level, patients completed the 30-item Motor Activity Log (MAL) [38], which assessed the amount (Amount of Use [AOU]) and the type (Quality of Movement [QOM]) of arm use in everyday life situations. Finally, social validity [39], defined as the social acceptability of the intervention and its impact on patients, was monitored by logging patients' comments throughout therapy. This also assessed patient satisfaction/dissatisfaction with therapy.

\section{Statistical Analysis}

Owing to the small sample size and heterogeneity, the authors used a single subject research design (SSRD) with baseline (pre-test 1, 
pre-test 2), immediate post-intervention (post-test) follow-up and (follow-up) contrasts [40]. SSRD alone or combined with case reports and group analysis has been used previously to evaluate treatment outcomes in children and adults with motor deficits [41-43].

Intervention effects for each clinical outcome in each patient were assessed by calculating effect sizes (ESs) obtained through standard mean differences. For single subject designs, the ES represents the proportion of points that are less than or greater than the average points in the baseline phase. The authors considered ES of $>0.30$ to be significant and those $>0.50$ to be large, as at this level, more than $69 \%$ of data points differ from the baseline $[44,45]$.

There were no differences between pre-test 1 and 2 scores for all of the outcome measures $(P$ values of paired $t$-tests ranged from 0.05 to $0.905)$ except for the WMFT mean score in the conventional group $(P<0.03)$. For these outcomes, the second pre-test scores were used as the baseline values for each test. For the WMFT mean score in the conventional group, the authors used the higher score of the two pre-tests. Between-mean differences of post-test or follow-up assessments were divided by pretest standard deviation (SD).

\section{RESULTS}

\section{Effect of Treatment}

All subjects in both groups completed all study phases. Groups were similar in age, gender, and time since lesion with no between-group differences (Table 1). The VR group included three men and three women and had a mean age of $58.1 \pm 14.6$ years. The Conventional group also included three men and three women with a mean age of $59.8 \pm 15.1$ years. Hand dominance was based on patient report of which hand was used for writing before the stroke (Table 1). Mean (SD) scores for all clinical outcomes for each group and time period are listed in Table 2. Mean values of initial, post-test and follow-up scores are listed for individual subjects in each group in Tables 3 and 4.

At the Body Structure and Function level, more patients in VR improved FMA scores at post-test compared to conventional therapy (VR: four of six; Conventional: one of six, Table 3). Two patients in the VR group and one in the conventional group maintained the improvement at follow-up. In the conventional group, two additional patients improved only at follow-up. Spasticity decreased in both groups (VR: three of six at post-test, four of six at followup; Conventional: two of six at post-test, four of six at follow-up). Changes in the RPSS also occurred in both groups, with four and three compared to three and four patients improving reaching performance at post-test and follow-up for VR and Conventional, respectively (Table 4).

At the Activity level, only one or two subjects improved performance on BBT in each group. However, there was a stronger effect of training on WMFT in the VR group (mean score) with five of six subjects improving at post-test compared to three of six subjects in the Conventional group. Improvements at followup were maintained in all five subjects in the VR group and in two of six subjects in the Conventional group. Timed WMFT scores improved in one to two subjects per group, but worsened in three of six subjects who received conventional training. This performance decrease was maintained in one of these subjects. In VR, one subject's performance on the timed WMFT worsened at post-test.

The frequency (MAL-AOU) and quality of (MAL-QOM) of daily arm use was unchanged in both groups (Table 2). However, patients in VR reported being more motivated to improve 
affected-arm reaching ability, that they felt more challenged by the intervention, and that their enjoyment of the activity helped them persist in the task even when it was difficult or they felt fatigued. Both patients and therapists reported a steady progression in the ability of patients to cope with an increasing level of difficulty as the VR intervention continued. In particular, VR participants commented on the realism of the experience, which was enhanced by the visual and auditory feedback during the games. All VR participants indicated that the VR-based exercise was more dynamic, interesting, meaningful, and motivating than their previously experienced exercises performed with conventional equipment and that participants tended to make more movements in the VR environment. Therapists noted that VR participants tended to take more initiative during therapy, requesting specific virtual tasks that they found to be effective. None of the patients, including the more elderly participants, regarded the need to cope with the VR technology as a deterrent to their participation, and no adverse effects of training in either environment were reported.

Table 1 Demographic data of patients with stroke

\begin{tabular}{|c|c|c|c|c|c|c|}
\hline & Age & Gender & Time since lesion (years) & Side of dominance ${ }^{a}$ & Side of hemiparesis & Lesion site \\
\hline \multicolumn{7}{|c|}{ Conventional therapy } \\
\hline 1 & 55.0 & $\mathrm{~F}$ & 3.1 & $\mathrm{R}$ & $\mathrm{R}$ & BG, IC \\
\hline 2 & 58.0 & M & 4.5 & $\mathrm{R}$ & $\mathrm{R}$ & - \\
\hline 3 & 75.0 & M & 3.8 & $\mathrm{R}$ & $\mathrm{R}$ & BG, IC \\
\hline 4 & 70.0 & $\mathrm{~F}$ & 2.7 & $\mathrm{R}$ & $\mathrm{L}$ & Corona radiata \\
\hline 5 & 68.0 & M & 3.7 & $\mathrm{R}$ & $\mathrm{L}$ & - \\
\hline 6 & 33.0 & $\mathrm{~F}$ & 5.0 & $\mathrm{R}$ & $\mathrm{L}$ & Frontotemporal, BG \\
\hline Mean & 59.8 & & 3.8 & & & \\
\hline SD & 15.1 & & 0.9 & & & \\
\hline \multicolumn{7}{|c|}{ Virtual reality therapy } \\
\hline 1 & 63.5 & $\mathrm{~F}$ & 3.0 & $\mathrm{~L}$ & $\mathrm{R}$ & - \\
\hline 2 & 66.0 & M & 3.7 & $\mathrm{R}$ & $\mathrm{L}$ & - \\
\hline 3 & 80.0 & M & 2.0 & $\mathrm{~L}$ & $\mathrm{R}$ & Frontal-parietal, BG, IC \\
\hline 4 & 50.0 & M & 2.0 & $\mathrm{R}$ & $\mathrm{R}$ & Posterior IC \\
\hline 5 & 39.0 & $\mathrm{~F}$ & 3.8 & $\mathrm{R}$ & $\mathrm{L}$ & Subcortical \\
\hline 6 & 50.0 & $\mathrm{~F}$ & 0.8 & $\mathrm{R}$ & $\mathrm{R}$ & Parietal-occipital \\
\hline Mean & 58.1 & & 2.6 & & & \\
\hline SD & 14.6 & & 1.2 & & & \\
\hline
\end{tabular}

$B G$ basal ganglia, $F$ female, $I C$ internal capsule, $L$ left, $M$ male, $R$ right

a Based on patient report of hand used for writing and other daily activities 
Table 2 Group mean (SD) data for clinical tests at four time periods: pre-test 1, pre-test 2, post-test, and follow-up test

\begin{tabular}{|c|c|c|c|c|}
\hline & Pre-test 1 & Pre-test 2 & Post-test & Follow-up test \\
\hline \multicolumn{5}{|c|}{ Body Structure and Function Level: Impairment } \\
\hline \multicolumn{5}{|l|}{$F M A(66)$} \\
\hline \multirow[t]{2}{*}{ Conventional } & 42.3 & 43.9 & 44.9 & 48.0 \\
\hline & $(13.6)$ & $(13.0)$ & $(11.7)$ & $(11.6)$ \\
\hline \multirow[t]{2}{*}{ Virtual reality } & 40.1 & 42.3 & 47.3 & 46.3 \\
\hline & $(13.6)$ & $(11.8)$ & $(11.9)$ & $(10.0)$ \\
\hline \multicolumn{5}{|l|}{ CSI (16) } \\
\hline \multirow[t]{2}{*}{ Conventional } & 8.5 & 9.2 & 8.7 & 7.5 \\
\hline & $(2.7)$ & $(2.2)$ & $(1.4)$ & $(1.0)$ \\
\hline \multirow[t]{2}{*}{ Virtual reality } & 7.7 & 7.2 & 6.2 & 6.0 \\
\hline & (1.9) & $(1.7)$ & $(2.9)$ & $(2.3)$ \\
\hline \multicolumn{5}{|l|}{ RPSS (18) } \\
\hline \multirow[t]{2}{*}{ Conventional } & 11.5 & 10.5 & 12.8 & 13.6 \\
\hline & $(4.7)$ & $(4.1)$ & $(3.6)$ & $(4.0)$ \\
\hline \multirow[t]{2}{*}{ Virtual reality } & 13.3 & 13.7 & 15.0 & 14.3 \\
\hline & $(4.1)$ & $(3.1)$ & $(3.0)$ & $(3.2)$ \\
\hline \multicolumn{5}{|c|}{ Activity Level: Function } \\
\hline \multicolumn{5}{|c|}{ BBT (\% less-affected side) } \\
\hline \multirow[t]{2}{*}{ Conventional } & 20.5 & 23.8 & 23.9 & 30.1 \\
\hline & $(18.6)$ & $(21.1)$ & $(21.2)$ & $(23.8)$ \\
\hline \multirow[t]{2}{*}{ Virtual reality } & 29.5 & 29.8 & 30.3 & 32.2 \\
\hline & $(26.9)$ & $(26.7)$ & $(27.7)$ & $(28.0)$ \\
\hline \multicolumn{5}{|l|}{$W M F T$ (total) } \\
\hline \multirow[t]{2}{*}{ Conventional } & 47.5 & 50.2 & 53.2 & 55.3 \\
\hline & $(13.6)$ & $(13.8)$ & $(20.0)$ & $(17.7)$ \\
\hline \multirow[t]{2}{*}{ Virtual reality } & 47.0 & 48.2 & 54.3 & 55.7 \\
\hline & $(16.4)$ & $(14.0)$ & $(16.1)$ & $(16.3)$ \\
\hline \multicolumn{5}{|l|}{ WMFT (time; s) } \\
\hline \multirow[t]{2}{*}{ Conventional } & 14.3 & 12.0 & 14.8 & 12.4 \\
\hline & $(11.5)$ & $(8.4)$ & $(13.4)$ & $(10.9)$ \\
\hline \multirow[t]{2}{*}{ Virtual reality } & 15.4 & 14.5 & 14.8 & 12.4 \\
\hline & $(9.1)$ & $(9.4)$ & $(10.5)$ & $(7.5)$ \\
\hline
\end{tabular}


Table 2 continued

\begin{tabular}{|c|c|c|c|c|}
\hline & Pre-test 1 & Pre-test 2 & Post-test & Follow-up test \\
\hline \multicolumn{5}{|c|}{ Participation Level: Participation } \\
\hline \multicolumn{5}{|l|}{$M A L-Q O M$} \\
\hline \multirow[t]{2}{*}{ Conventional } & 1.18 & 1.27 & 1.72 & 1.80 \\
\hline & $(1.53)$ & $(1.51)$ & $(1.84)$ & $(2.06)$ \\
\hline \multirow[t]{2}{*}{ Virtual reality } & 1.22 & 1.18 & 1.08 & 1.37 \\
\hline & $(1.14)$ & $(1.15)$ & $(1.08)$ & $(1.32)$ \\
\hline \multicolumn{5}{|l|}{$M A L-A O U$} \\
\hline \multirow[t]{2}{*}{ Conventional } & 1.18 & 1.23 & 1.65 & 1.57 \\
\hline & $(1.57)$ & $(1.53)$ & $(1.87)$ & $(1.92)$ \\
\hline \multirow[t]{2}{*}{ Virtual reality } & 1.10 & 1.13 & 1.08 & 1.20 \\
\hline & $(1.06)$ & $(1.05)$ & $(1.12)$ & $(1.15)$ \\
\hline
\end{tabular}

AOU Amount of Use, BBT Box and Blocks, CSI Composite Spasticity Index, FMA Fugl-Meyer Assessment, MAL Motor Activity Log, QOM Quality of Movement, RPSS Reaching Performance Scale for Stroke, WMFT Wolf Motor Function Test

\section{DISCUSSION}

The authors evaluated the potential of a $2 \mathrm{D}$ video-capture VR training environment to improve UL motor ability in stroke patients compared to conventional therapy via a small sample RCT. Although improvements occurred in both groups, more patients in VR improved UL clinical impairment at the ICF Body Structure and Function Level (FMA, CSI) as well as scores at the Activity level of the ICF (WMFT). Changes did not occur at the Performance level and the WMFT was found to be more sensitive to post-practice changes than the MAL. Participants expressed satisfaction with the novel treatment.

The authors found that clinical impairment and activity improved to the same or better extent when therapy was delivered in the $2 \mathrm{D} V R$ environment as compared to the conventional physical environment. These improvements occurred in spite of evidence that movement patterns used to produce reaching movements might be different from those performed in physical environments for equivalent tasks. In a study comparing the kinematics of reaching into different parts of the arm workspace in an IREX VR environment, movements were made in a substantially different way from those made to equivalent targets in a physical environment [26]. That study concluded that movements in the 2D VR environment were affected by the lack of environmental depth cues [46] such that sagittally directed reaching movements were viewed as occurring in the coronal plane. Nevertheless, in spite of the potentially altered movement patterns in the video-capture VR, improvements in clinical impairment and activity occurred.

One explanation for better clinical outcomes is that the VR environment allowed patients to practice different combinations of joint rotations that were unconstrained by physical task requirements (e.g., having to adopt a specific orientation of the hand to enable grasping of a physical object). Thus, by practicing movement combinations with fewer constraints in VR, 


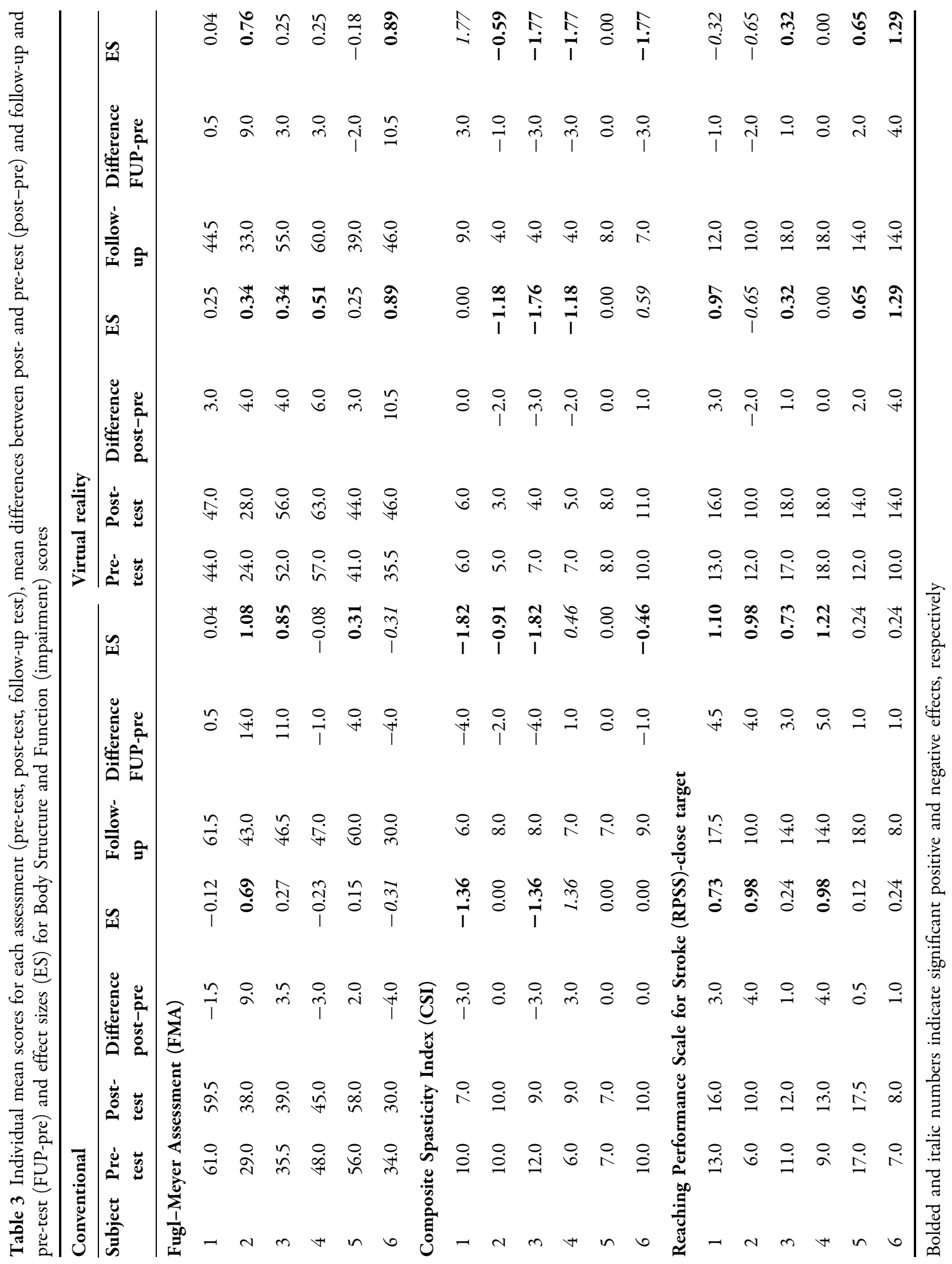


Table 4 Individual mean differences between post- and pre-tests (post-pre) and between follow-up and pre-tests (FUP-pre), and effect sizes (ES) for scores on functional scales

\begin{tabular}{|c|c|c|c|c|c|c|c|c|}
\hline \multicolumn{5}{|c|}{ Conventional } & \multicolumn{4}{|l|}{ Virtual reality } \\
\hline Subject & $\begin{array}{l}\text { Difference post- } \\
\text { pre }\end{array}$ & ES & $\begin{array}{l}\text { Difference FUP- } \\
\text { pre }\end{array}$ & ES & $\begin{array}{l}\text { Difference post- } \\
\text { pre }\end{array}$ & ES & $\begin{array}{l}\text { Difference FUP- } \\
\text { pre }\end{array}$ & ES \\
\hline \multicolumn{9}{|l|}{ BBT } \\
\hline 1 & -1.92 & -0.09 & 5.74 & 0.27 & -4.34 & -0.16 & -6.44 & -0.24 \\
\hline 2 & 0.00 & 0.00 & 0.00 & 0.00 & -3.28 & -0.12 & -2.91 & -0.11 \\
\hline 3 & 0.20 & 0.01 & -3.46 & -0.16 & -0.13 & 0.00 & 12.95 & 0.49 \\
\hline 4 & -3.01 & -0.14 & -2.63 & -0.13 & 5.39 & 0.20 & 2.31 & 0.09 \\
\hline 5 & 5.46 & 0.26 & 7.97 & 0.38 & -3.86 & -0.14 & -0.89 & -0.03 \\
\hline 6 & 0.00 & 0.00 & 0.00 & 0.00 & 9.45 & 0.35 & 9.45 & 0.35 \\
\hline \multicolumn{9}{|c|}{ WMFT (mean) } \\
\hline 1 & 11.0 & 0.59 & 14.0 & 0.75 & 6.0 & 0.43 & 4.0 & 0.29 \\
\hline 2 & 1.0 & 0.05 & 4.0 & 0.22 & 6.0 & 0.43 & 8.0 & 0.57 \\
\hline 3 & 9.0 & 0.48 & 5.0 & 0.27 & 10.0 & 0.71 & 14.0 & 1.00 \\
\hline 4 & 0.0 & 0.00 & 4.0 & 0.22 & 8.0 & 0.57 & 8.0 & 0.57 \\
\hline 5 & 7.0 & 0.38 & 6.0 & 0.32 & 6.0 & 0.43 & 10.0 & 0.71 \\
\hline 6 & -10.0 & -0.54 & -2.0 & -0.11 & 1.0 & 0.07 & 1.0 & 0.07 \\
\hline \multicolumn{9}{|c|}{ WMFT (time) } \\
\hline 1 & -1.26 & -0.15 & -1.53 & -0.18 & -2.95 & -0.31 & 1.10 & 0.12 \\
\hline 2 & 4.26 & 0.51 & 1.63 & 0.19 & 4.46 & 0.47 & -1.47 & -0.16 \\
\hline 3 & -7.30 & -0.87 & -6.41 & -0.76 & -0.30 & -0.03 & -1.16 & -0.12 \\
\hline 4 & 6.80 & 0.81 & 0.97 & 0.12 & -0.89 & -0.10 & -0.71 & -0.08 \\
\hline 5 & 0.15 & 0.02 & 0.69 & 0.08 & 2.49 & 0.26 & -4.36 & -0.46 \\
\hline 6 & 14.07 & 1.67 & 7.18 & 0.86 & -0.86 & -0.09 & -5.79 & -0.62 \\
\hline
\end{tabular}

Bolded and italicized numbers indicate significant positive and negative effects, respectively $B B T$ Box and Blocks Test; WMFT Wolf Motor Function Test

patients may have learned more effective ways to combine joint rotations to accomplish tasks on clinical tests [47]. Having more effective movement does not necessarily imply that the movement is of better quality. In our study, not all of the functional improvements were accompanied by improvements in movement quality. Indeed, only one subject (subject 1 ) in the conventional group improved both UL function (WMFT) and arm movement quality (RPSS), whereas a larger number of patients in the VR group (three; patients 1, 3, and 5) improved both function and quality (Tables 3,4 ). A better understanding of whether compensatory movement patterns accounted for clinical improvements can only be gained by a 
concomitant analysis of movement kinematics [48].

Specific attributes of the VR system may have accounted for better outcomes in the VR group. These include the opportunity to practice tasks in a variety of simulated settings in which patients may be motivated to interact repeatedly, and that the level of difficulty of the activity can be graded to the motor ability level of the patient. Another important attribute is the provision of different types of feedback. Feedback during VR treatment was provided by the therapist in combination with system-based feedback. The enhanced feedback in the VR environment may have allowed patients to learn more effective movement through both extrinsic and intrinsic mechanisms [49]. Indeed, a recent study comparing practice in VR and conventional environments that was matched for intensity and feedback concluded that patients in the VE group incorporated feedback more effectively than those in the conventional environment as improvements in reaching movements were obtained with less motor compensation [50].

Two-dimensional video-capture environments have the potential to be used in rehabilitation as they are relatively low cost, easy to use, and developed specifically to address rehabilitation goals such as sitting and standing balance and goal-directed reaching [19]. However, this environment has specific characteristics that likely influence its effectiveness for UL rehabilitation. In a video-capture VR environment, users see a projected mirror image of themselves (third-person view) instead of a firstperson view, which includes their virtual arm and/ or hand. When movements are performed from a first-person perspective, kinesthetic information is fed back to the system from the moving arm. However, from a third-person perspective, visual and kinesthetic information do not match, requiring a visuomotor transformation [51]. In healthy subjects, movement representations may be comparable when viewed from different perspectives as the time to complete a grasping movement is similar during executed or imagined tasks from a first- or third-person perspective [52]. However, this may not be true when visuomotor transformation areas such as parietal cortex sustain stroke-related damage [53]. Nevertheless, the finding of the current study, that patients with stroke could improve clinical outcomes when practicing in $2 \mathrm{D}$ video-capture VE alone, suggests they were able to derive benefits of the VE practice environment regardless of the potential differences in sensorimotor representation and transformation. The positive results of UL practice in VE suggest that it may be considered as an adjunct treatment in clinical settings to increase the amount of arm movements and, hence, the intensity of UL rehabilitation.

\section{Study Limitations}

Despite these encouraging results, it is not yet possible to conclude from this and other studies that VR is more effective than conventional UL therapy because of the small sample size. However, the current advantage of VR training over conventional training (i.e., more and earlier changes in UL performance), adds to the steadily increasing body of evidence and supports further investigation of the effect of video-capture VR alone or as an adjunctive therapy combined with conventional therapy in larger-scale RCTs.

\section{ACKNOWLEDGMENTS}

The authors certify that no party having a direct interest in the results of the research supporting this article has or will confer a benefit on us or on any organization with which we are associated 
and we certify that all financial and material support for this research (e.g., NIH or NHS grants) and work are clearly identified here. This work was supported by FRSQ-REPAR International Collaborative Grant, Israel Ministry of Health no. 3-00000-4227. Sheba Medical Center, Tel Hashomer, Israel, hosted the study and provided access to patients. Dr. Levin is the guarantor for this article, and takes responsibility for the integrity of the work as a whole.

Conflict of Interest. None of the authors declare any conflicts of interest.

Open Access. This article is distributed under the terms of the Creative Commons Attribution Noncommercial License which permits any noncommercial use, distribution, and reproduction in any medium, provided the original author(s) and the source are credited.

\section{REFERENCES}

1. Kwakkel G, Kollen BJ, van der Grond J, Prevo AJ. Probability of regaining dexterity in the flaccid upper limb: impact of severity of paresis and time since onset in acute stroke. Stroke. 2003;34:2181-6.

2. Mayo NE, Wood-Dauphinee S, Cote R, Durcan L, Carlton J. Activity, participation, and quality of life 6 months poststroke. Arch Phys Med Rehabil. 2002;83:1035-42.

3. Maldonado MA, Allred RP, Felthauser EL, Jones TA. Motor skill training, but not voluntary exercise, improves skilled reaching after unilateral ischemic lesions of the sensorimotor cortex in rats. Neurorehabil Neural Repair. 2008;22:250-61.

4. Proteau L, Blandin Y, Alain C, Dorion A. The effects of the amount and variability of practice on the learning of a multi-segmented motor task. Acta Psychol. 1994;85:61-74.

5. Winstein CJ, Merians AS, Sullivan KJ. Motor learning after unilateral brain damage. Neuropsychologia. $1999 ; 37: 975-87$.

6. Kantak SS, Sullivan KJ, Fisher BE, Knowlton BJ, Winstein CJ. Neural substrates of motor memory consolidation depend on practice structure. Nat Neurosci. 2010;13:923-5.

7. Kwakkel G, Wagenaar RC, Koelman TW, Lankhorst GJ, Koetsier JC. Effects of intensity of rehabilitation after stroke. A research synthesis. Stroke. 1997;28:1550-6.

8. Kleim JA, Jones TA. Principles of experiencedependent neural plasticity: implications for rehabilitation after brain damage. J Speech Lang Hear Res. 2008;51:S225-39.

9. Cirstea CM, Ptito A, Levin MF. Feedback and cognition in arm motor skill reacquisition after stroke. Stroke. 2006;37:1237-42.

10. Nudo RJ, Milliken GW. Reorganization of movement representations in primary motor cortex following focal ischemic infarcts in adult squirrel monkeys. J Neurophysiol. 1996;75:2144-9.

11. Rizzo A. Virtual reality and disability: emergence and challenge. Disabil Rehabil. 2002;24:567-9.

12. Rizzo AA, Kim GJ. A SWOT analysis of the field of VR rehabilitation and therapy. Presence-TeleopVirt. 2005;14:119-46.

13. Weiss PL, Ring H. Commentary on virtual reality in stroke rehabilitation: still more virtual than real. Disabil Rehabil. 2007;29:1147-9.

14. You SH, Jang SH, Kim YH, et al. Virtual reality-induced cortical reorganization and associated locomotor recovery in chronic stroke: an experimenter-blind randomized study. Stroke. 2005;36:1166-71.

15. Holden MK. Virtual environments for motor rehabilitation: review. Cyberpsychol Behav. 2005;8:187-211.

16. Henderson AK, Korner-Bitensky N, Levin MF. Virtual reality in stroke rehabilitation: a systematic review of its effectiveness for upper limb motor recovery. Top Stroke Rehabil. 2007;14:52-61.

17. Adamovich SV, Fluet GG, Tunik E, Merians AS. Sensorimotor training in virtual reality: a review. Neurorehabilitation. 2009;25:29-44.

18. Lucca LF. Virtual reality and motor rehabilitation of the upper limb after stroke: a generation of progress? J Rehabil Med. 2009;41:1003-6.

19. Weiss PL, Sveistrup H, Rand D, Kizony R. Video capture virtual reality: a decade of rehabilitation assessment and intervention. Phys Ther Rev. 2009;14:307-21.

20. Crosbie JH, Lennon S, Basford JR, McDonough SM. Virtual reality in stroke rehabilitation: still more virtual than real. Disabil Rehabil. 2007;29:1139-46. 
21. Mumford N, Wilson PH. Virtual reality in acquired brain injury upper limb rehabilitation: evidencebased evaluation of clinical research. Brain Inj. 2009;23:179-91.

22. Laver KE, George S, Thomas S, Deutsch JE, Crotty M. Virtual reality for stroke rehabilitation. Cochrane Database Syst Rev. 2011;9:CD008349.

23. Saposnik G, Levin MF. Virtual reality in stroke rehabilitation: a metanalysis and implications for clinicians. Stroke. 2011;42:1380-6.

24. Creem-Regeh SH, Willemsen $\mathrm{P}$, Gooch AA, Thompson WB. The influence of restricted viewing conditions on egocentric distance perception: implications for real and virtual environments. Perception. 2005;34:191-204.

25. Magdalon EC, Michaelsen SM, Quevedo AAF, Levin MF. Comparison of grasping movements made by healthy subjects in a 3-dimentional immersive virtual versus physical environment. Acta Psychol (Amst). 2011;138:126-34.

26. Liebermann DG, Berman S, Weiss PL, Levin MF. Kinematics of reaching movements in a $2 \mathrm{D}$ virtual environment in adults with and without stroke. IEEE Trans Neural Syst Rehab Eng. 2012. (In press).

27. Knaut LA, Subramanian S, McFadyen BJ, Bourbonnais D, Levin MF. Kinematics of pointing movements made in a virtual versus a physical 3D environment in stroke. Arch Phys Med Rehabil. 2009;90:793-802.

28. IOM: Institute of Medicine. Small Clinical Trials: Issues and Challenges. Washington: National Academies; 2001.

29. Jack D, Boian R, Merians AS, et al. Virtual realityenhanced stroke rehabilitation. IEEE Trans Neural Syst Rehab Eng. 2011;9:308-18.

30. Folstein MF, Folstein SE, McHugh PR. "Mini-mental state". A practical method for grading the cognitive state of patients for the clinician. J Psychiatr Res. 1975;12:189-98.

31. Rand D, Katz N, Weiss PL. Evaluation of virtual shopping in the VMall: comparison of post-stroke participants to healthy control groups. Disabil Rehabil. 2007;29:1710-9.

32. World Health Organization. ICF: International Classification of Functioning, Disability and Health. Geneva: World Health Organization; 2001.

33. Fugl-Meyer AR, Jääsko L, Leyman L, Olsson S, Steglind S. The post-stroke hemiparetic patient. I. A method for evaluation of physical performance. Scand J Rehab Med. 1975;7:13-31.
34. Levin MF, Hui-Chan CW. Relief of hemiparetic spasticity by TENS is associated with improvement in reflex and voluntary motor functions. Electroencephalogr Clin Neurophysiol. 1992;85: $131-42$.

35. Levin MF, Desrosiers J, Beauchemin D, Bergeron N, Rochette A. Development and validation of a scale for rating motor compensations used for reaching in patients with hemiparesis: the reaching performance scale. Phys Ther. 2004;84:8-22.

36. Mathiowetz V, Volland G, Kashman N, Weber K. Adult norms for the Box and Block Test of manual dexterity. Am J Occup Ther. 1985;39:386-91.

37. Wolf SL, Catlin PA, Ellis M, Archer AL, Morgan B, Piacentino A. Assessing Wolf motor function test as outcome measure for research in patients after stroke. Stroke. 2001;32:1635-9.

38. Uswatte G, Taub E, Morris D, Light K, Thompson PA. The Motor Activity Log-28: assessing daily use of the hemiparetic arm after stroke. Neurology. 2006;67:1189-94.

39. Schwartz IS, Baer DM. Social validity assessments: is current practice state of the art? J Appl Behav Anal. 1991;24:189-204.

40. Barlow DH, Nock MK, Hersen M. Single case experimental designs-strategies for studying behavior change. Boston: Pearson Education; 2009.

41. Trahan J, Malouin F. Intermittent intensive physiotherapy in children with cerebral palsy: a pilot study. Dev Med Child Neurol. 2002;44:233-9.

42. Schneiberg S, Mckinley P, Sveistrup H, Gisel E, Mayo NE, Levin MF. Task-oriented intervention and trunk restraint on upper limb movement quality in children with cerebral palsy. Dev Med Child Neurol. 2010;52:e245-53.

43. Saposnik G, Mamdani M, Bayley M, Thorpe KE, Hall $\mathrm{J}$, Cohen LG, Teasell R, EVREST Steering Committee, EVREST Study Group for the Stroke Outcome Research Canada Working Group. Effectiveness of Virtual Reality Exercises in STroke Rehabilitation (EVREST): rationale, design, and protocol of a pilot randomized clinical trial assessing the Wii gaming system. Int J Stroke. 2010;5:47-51.

44. Scruggs TE, Mastropieri MA. Summarizing singlesubject research: issues and applications. Behav Modif. 1994;22:221-42.

45. Campbell JM. Statistical comparison of four effect sizes for single-subject designs. Behav Modif. 2004;28:234-46. 
46. Bingham GP, Pagano C. The necessity of a perception/action approach to definite distance perception: monocular distance perception to guide reaching. J Exp Psych Human Perc Perf. 1998;24:145-68.

47. Bernstein NA. The Co-ordination and Regulation of Movements. Chapter II. The problem of the interrelation of co-ordination and localization, Oxford: Pergamon Press; 1967:15-60.

48. Levin MF, Kleim JF, Wolf S. What do motor 'recovery' and 'compensation' mean in patients following stroke? Neurorehabil Neural Repair. 2009;23:313-9.

49. Subramanian SK, Massie CL, Malcolm MP, Levin MF. Does provision of extrinsic feedback result in improved motor learning in the upper limb poststroke? A systematic review of the evidence. Neurorehabil Neural Repair. 2010;24:113-24.
50. Subramanian SK, Lourenco CB, Chilingaryan G, Sveistrup H, Levin MF. Arm motor recovery using virtual reality intervention in chronic stroke: randomized control trial. Neurorehabil Neural Repair. 2012. [Epub ahead of print].

51. Grezes J, Decety J. Functional anatomy of execution, mental simulation, observation, and verb generation of actions: a meta-analysis. Hum Brain Mapp. 2001;12:1-19.

52. Anquetil T, Jeannerod M. Simulated actions in the first and in the third person perspectives share common representations. Brain Res. 2007;1130: $125-9$.

53. Newport R, Brown L, Husain M, Mort D, Jackson SR. The role of the posterior parietal lobe in prism adaptation: failure to adapt to optical prisms in patients with bilateral damage to posterior parietal cortex. Cortex. 2006;42:720-9. 